\title{
FORMULASI DAN UJI DAYA HAMBAT SABUN CAIR EKSTRAK ETANOL SERAI WANGI (Cymbopogon nardus L) TERHADAP PERTUMBUHAN Staplylococcus aureus
}

\author{
Rinaldi $^{1 *}$, Fauziah $^{2}$, Rizka Mastura $^{3}$ \\ 1,2,3 Akademi Analis Farmasi dan Makanan Banda Aceh, Indonesia \\ Email korespondensi: erixaza79@gmail.com
}

\begin{abstract}
ABSTRAK
Serai wangi (Cymbopogon Nardus.L) mengandung senyawa minyak atsiri, saponin, polifenol dan flavonoid yang bersifat sebagai antibakteri. Pemanfaatan senyawa aktif serai wangi diformulasikan ke dalam sediaan sabun cair antibakteri. Penelitian ini bertujuan untuk mengetahui karakteristik sabun cair dan daya hambat terhadap pertumbuhan Staphylococcus aureus. Penelitian ini bersifat eksperimental untuk memformulasikan sabun cair yang mengandung ekstrak etanol batang serai wangi pada konsentrasi 9\% (F1), $18 \%$ (F2) dan 24\% (F3). Parameter uji sediaan sabun cair meliputi uji organoleptis (bentuk, aroma, warna), uji homogenitas, uji $\mathrm{pH}$, uji tinggi busa, uji kestabilan busa, uji alkali bebas dan uji daya hambat terhadap pertumbuhan Staphylococcus aureus dengan metode KirbyBauer. Hasil penelitian menunjukan sediaan sabun cair pada formula F1, F2 dan F3 berbentuk cair, aroma khas serai wangi dan berwarna coklat, homogen. Nilai pH, tinggi busa, stabilitas busa dan kadar alkali bebas sabun cair secara berurutan masing-masingnya adalah F1 (12; $70 \mathrm{~mm} ; 85,7 \%$ dan 0,14\%), F2 (11, $80 \mathrm{~mm}, 87,5 \%$ dan 0,10\%), F3 (10, 100 $\mathrm{mm}, 90 \%$ dan $0,08 \%$ ). Diameter zona hambat formula secara berurutan yaitu 32,06 mm, 25,6 mm dan 29,2 mm. Sehingga dapat disimpulkan bahwa karakteristik sediaan sabun cair ekstrak etanol batang Serai Wangi (Cymbopogon Nardus.L) memenuhi persyaratan sebagai sabun cair. Efektivitas daya hambat terhadap pertumbuhan Staphylococcus aureus terbesar adalah formula pada kosentrasi $24 \%$ (F3) dengan kategori kuat.
\end{abstract}

Kata kunci: sabun cair, Formulasi, daya hambat, Staphylococus aureus 


\title{
FORMULATION AND INHITION OF LIQUID SOAP ETHANOL EXTRACT CITRONELLA (Cymbopogon nardus L) ON THE GROWTH OF Staplylococcus aureus
}

\begin{abstract}
Citronella (Cymbopogon Nardus.L) contains essential oil compounds, saponins, polyphenols and flavonoids which are antibacterial. The use of active compounds of Citronella is formulated into antibacterial liquid soap preparations. This study aims to determine the characteristics of liquid soap and its inhibition against the growth of Staphylococcus aureus. This research is experimental to formulate liquid soap containing ethanol extract of lemongrass sticks at concentrations of 9\% (F1), 18\% (F2) and 24\% (F3). The test parameters for liquid soap preparations include organoleptic test (shape, aroma, color), homogeneity test, pH test, foam height test, foam stability test, free alkaline test and inhibition test against the growth of Staphylococcus aureus using the Kirby-Bauer method. The results showed that the liquid soap preparations in the F1, F2 and F3 formulas were liquid, had a distinctive aroma of Citronella and were brown in color, homogeneous. The pH values, foam height, foam stability and free alkaline content of liquid soap were F1 (12; $70 \mathrm{~mm} ; 85.7 \%$ and $0.14 \%$ ), F2 (11. $80 \mathrm{~mm}, 87.5 \%$ and respectively). $0.10 \%), F 3$ (10.100 $\mathrm{mm}, 90 \%$ and $0.08 \%$ ). The formula inhibition zone diameters are $32.06 \mathrm{~mm}, 25.6 \mathrm{~mm}$ and $29.2 \mathrm{~mm}$, respectively. The conclution is the characteristics of the liquid soap with the ethanol extract of Citronella (Cymbopogon Nardus.L) meet the requirements as liquid soap. The greatest inhibitory effectiveness on the growth of Staphylococcus aureus was a formula at a concentration of $24 \%$ (F3) with a strong category.
\end{abstract}

Keywords: Liquid soap, Formulation, Inhibition, Staphylococus aureus

\section{PENDAHULUAN}

Sabun cair merupakan salah satu sediaan kosmetika berbentuk cair yang digunakan untuk membersihkan kulit, terbuat dari bahan dasar sabun dan ditambahkan bahan lainnya seperti surfaktan, pengawet, penstabil busa, pewangi dan pewarna dan dapat digunakan untuk mandi tanpa menimbulkan iritasi pada kulit (BSN, 1996)

Kulit harus dijaga dan dibersihkan

dari kotoran-kotoran. Kotoran yang melekat pada kulit merupakan media yang baik bagi bakteri. Sabun antibakteri dapat digunakan dan dipercaya dapat membersihkan kulit sekaligus sebagai pencegahan terjadinya infeksi kulit. Kulit 
merupakan bagian terluar tubuh yang secara langsung berkontak dengan lingkungan. Infeksi pada kulit dapat menyebabkan berbagai penyakit seperti dermatitis, impetigo dan selulitis. Bakteri yang umumnya menginfeksi kulit yaitu Staphylococcus aureus (Tong et al., 2015).

Pencegahan infeksi pada kulit dapat diatasi dengan penggunaan sabun yang mengandung senyawa bersifat sebagai antibakteri. Sabun antibakteri pada umumnya menggunakan bahan kimia antibakteri Triclocarban. Triclocarban menurut Food and Drug Association (FDA) dapat menyebabkan efek samping resistensi jika digunakan dalam jangka waktu yang lama (Sukawaty et al., 2016).

Senyawa antibakteri dari bahan alam merupakan sebagai alternatif untuk menghindari efek samping yang ditimbulkan oleh triclocarban. Senyawa metabolit sekunder seperti saponin, flavonoid, minyak atsiri dan senayawa lainnya bersifat sebagai antibakteri dengan daya kerja bakteriostatik atau bakteriosida.

Tanaman serai wangi telah terbukti mempunyai aktifitas antibakteri terhadap Escherichia coli dan Staphylococcus aureus dan diketahui pula bahwa tanaman serai wangi mengandung flavonoid, polifenol, saponin dan minyak atsiri (Basuki, 2011)

\section{METODE PENELITIAN}

Penelitian ini bersifat eksperimental untuk memformulasikan sabun cair yang mengandung ekstrak etanol batang serai wangi pada konsentrasi 9\% (F1), 18\% (F2) dan 24\% (F3). Sediaan dievaluasi dengan uji meliputi uji organoleptis (bentuk, aroma, warna), uji homogenitas, uji $\mathrm{pH}$, uji tinggi busa, uji kestabilan busa, uji alkali bebas dan uji daya hambat terhadap pertumbuhan Staphylococcus aureus dengan metode Kirby-Bauer

\section{Bahan dan Alat}

Bahan yang digunakan dalam penelitian ini yaitu serai wangi (Cymbopogon Nardus L) yang diambil dari desa Lamteuba kecamatan Seulimum Kabupaten Aceh Besar, suspensi bakteri Staphylacoccus aureus, minyak zaitun, kalium hidroksida $(\mathrm{KOH})$, Natrium karboksil metal selulosa (CMC), Sodium lauril sulfat, asam stearat, EDTA, fenolftalein, etanol 96\%, Nutrien Agar (NA), Mueller Hinton Agar (MHA), Barium klorida hidrat $\left(\mathrm{BaCl}_{2} \mathrm{H}_{2} \mathrm{O}\right) 1 \%$, Asam sulfat $\left(\mathrm{H}_{2} \mathrm{SO}_{4}\right) \quad 1 \%$, Chloramphenichol, $\mathrm{NaCl} 0,9 \%, \mathrm{HCl} 0,1$ $\mathrm{N}$, kain flannel, kertas ubi dan aluminium foil.

Alat yang digunakan dalam penelitian yaitu: $\mathrm{pH}$ meter, alat-alat gelas, penggaris, jarum ose, pinset timbangan analitik, cawan petri, inkubator, autoklaf, oven, blender, rotary evaporator, penangas air. 
PROSEDUR KERJA

Formulasi Sabun Cair
Ekstrak etanol serai wangi dengan konsentrasi ekstrak yang berbeda diformulasikan seperti pada Tabel 1 berikut.

Tabel 1. Formulasi sabun cair ekstrak etanol serai wangi

\begin{tabular}{lllll}
\hline Nama Bahan & Fo & F1 & F2 & F3 \\
\hline Ekstrak serai & $0 \mathrm{~g}$ & $9 \mathrm{~g}$ & $18 \mathrm{~g}$ & $24 \mathrm{~g}$ \\
Minyak zaitun & $30 \mathrm{ml}$ & $30 \mathrm{ml}$ & $30 \mathrm{ml}$ & $30 \mathrm{ml}$ \\
KOH $40 \%$ & $16 \mathrm{ml}$ & $16 \mathrm{ml}$ & $16 \mathrm{ml}$ & $16 \mathrm{ml}$ \\
CMC & $1 \mathrm{~g}$ & $1 \mathrm{~g}$ & $1 \mathrm{~g}$ & $1 \mathrm{~g}$ \\
S L S & $1 \mathrm{~g}$ & $1 \mathrm{~g}$ & $1 \mathrm{~g}$ & $1 \mathrm{~g}$ \\
Asam Stearat & $0,5 \mathrm{~g}$ & $0,5 \mathrm{~g}$ & $0,5 \mathrm{~g}$ & $0,5 \mathrm{~g}$ \\
EDTA & $1 \mathrm{~g}$ & $1 \mathrm{~g}$ & $1 \mathrm{~g}$ & $1 \mathrm{~g}$ \\
Parfum & $2 \mathrm{ml}$ & $2 \mathrm{ml}$ & $2 \mathrm{ml}$ & $2 \mathrm{ml}$ \\
Aq. ad & $100 \mathrm{ml}$ & $100 \mathrm{ml}$ & $100 \mathrm{ml}$ & $100 \mathrm{ml}$ \\
\hline
\end{tabular}

Ket:

F0 = Formula sabun cair yang tidak mengandung ekstrak etanol serai wangi

$\mathrm{F} 1=$ Formula sabun cair yang mengandung ekstrak etanol serai wangi $9 \%$

F2 = Formula sabun cair yang mengandung ekstrak etanol serai wangi $18 \%$

F3 = Formula sabun cair yang mengandung ekstrak etanol serai wangi $24 \%$

\section{Pembuatan Ekstrak Etanol Serai wangi.}

Ditimbang Serbuk kering serai wangi sebanyak 50 gram masukkan ke dalam beaker glass, kemudian ditambah $500 \mathrm{~mL}$ etanol 96\%. Ditutup wadah maserasi dengan aluminium foil dan dibiarkan selama 6 jam pertama sambil diaduk sesekali, diamkan kembali selama 18 jam, kemudian diserkai dengan kain flanel (Filtrat 1). Melalui ampasnya ditambahkan pelarut etanol $96 \%$ sebanyak $500 \mathrm{~mL}$, ditutup wadah maserasi dengan aluminium foil dan dibiarkan selama 6 jam sambil diaduk sesekali, diamkan kembali selama 18 jam kemudian diserkai dengan kain flanel (filtrat 2), digabungkan kedua filtrat dan diamkan selama 1 jam. 
Dilakukan enap-tuang Lalu diuapkan diatas penangas air dengan menggunakan cawan porselin hingga diperoleh ekstrak kental.

\section{Pembuatan Sediaan Formula Sabun cair.}

Semua bahan yang akan digunakan ditimbang terlebih dahulu sesuai dengan takaran yang dianjurkan. Dimasukkan minyak zaitun sebanyak 30 $\mathrm{ml}$ ke dalam gelas kimia, kemudian ditambahkan dengan Kalium hidroksida $40 \%$ sebanyak $16 \mathrm{ml}$ sedikit demi sedikit sambil terus dipanaskan pada suhu $50^{\circ} \mathrm{C}$ hingga mendapatkan massa pasta kental. Massa pasta ditambahkan dengan kurang lebih $15 \mathrm{ml}$ aquades, lalu dimasukkan Natrium karboksil metal selulosa (CMC) yang telah dikembangkan dalam aquades panas, diaduk hingga homogen. Kemudian ditambahkan asam stearat, diaduk hingga homogen. Ditambahkan Sodium lauril sulfat, diaduk hingga homogen. Ditambahkan EDTA, lalu diaduk hingga homogen. Dimasukkan ekstrak Serai (Cymbopogon nardus L.) pada masing-masing formula, pada formula F0 tanpa ekstrak serai, formula F1 (9 g) formula F2 (18 g), dan formula F3 (24 g) diaduk hingga homogen. Campuran ditambahkan dengan aquades hingga volumenya $100 \mathrm{ml}$, dimasukkan ke dalam wadah botol bersih yang telah disiapkan.

\section{Sterilisasi alat}

Alat-alat yang tahan pemanasan seperti cawan petri, tabung reaksi,
Erlenmeyer, beaker glass disterilkan dengan pemanasan kering di dalam oven pada suhu $180^{\circ} \mathrm{C}$ selama $1 \mathrm{jam}$. Ose bulat dipanaskan pada lampu spiritus sampai pijar. Pinset dipijarkan diatas lampu spiritus. Media biakan bakteri MHA dan NA disterilkan dengan autoklaf pada suhu $121^{\circ} \mathrm{C}$ selama 15 menit.

\section{Pembuatan Media Nutrient Agar (NA)}

Ditimbang NA sebanyak 1,4 gram, kemudian dimasukkan kedalam Erlenmayer, ditambahkan aquadest sebanyak $70 \mathrm{ml}$ diaduk rata dan dipanaskan sampai larut, lalu disterilkan dalam autoclave pada suhu $121^{\circ} \mathrm{C}$ selama 15 menit ditunggu sampai dingin antara $45^{\circ} \mathrm{C}$. Lalu bagikan ke dalam 3 petridis, masing-masing $20 \mathrm{ml}$. tunggu sampai memadat kemudian dibungkus dengan kertas ubi disimpan dalam kulkas sebelum digunakan.

\section{Pembuatan Media Mueller Hinton Agar (MHA)}

Timbang MHA sebanyak 2,38 gram, dimasukkan kedalam Erlenmeyer, lalu ditambahkan aquadest sebanyak 70 ml. diaduk rata dengan batang pengaduk dan dipanaskan sampai mendidih. Kemudian, disterilkan dalam autoclave pada suhu $121^{\circ} \mathrm{C}$ selama 15 menit, setelah itu dikeluarkan dari autoclave dan biarkan agak dingin pada suhu $45^{\circ} \mathrm{C}$ (MHA didinginkan agar tidak terjadi kondensasi air pada saat penuangan). Lalu bagikan kedalam 3 petridis, masing-masing $20 \mathrm{ml}$. tunggu sampai memadat kemudian 
dibungkus dengan kertas ubi disimpan dalam kulkas sebelum digunakan.

\section{Pembuatan Suspensi Standar Mc}

Farland 0,5

Suspensi Mc Farland dibuat dengan mencampurkan 0,05 $\mathrm{ml}$ larutan barium klorida hidrat $\left(\mathrm{BaCl}_{2} \mathrm{H}_{2} \mathrm{O}\right) \quad 1 \%$ ditambahkan 9,95 $\mathrm{ml}$ asam sulfat $\left(\mathrm{H}_{2} \mathrm{SO}_{4}\right)$ $1 \%$ kemudian dimasukkan kedalam tabung yang memakai tutup dan ditutup dengan kuat.

\section{Pembuatan Kultur Bakteri}

\section{Staphylococcus aureus}

Biakan bakteri Staphylococcus aureus digoreskan sebanyak satu ose pada media Nutrient Agar (NA) secara zig-zag. Kemudian diinkubasi di dalam inkubator pada suhu $37^{\circ} \mathrm{C}$ selama 24 jam.

\section{Pembuatan Suspensi Bakteri}

Staphylococcus aureus

Bakteri Staphylococcus aureus diambil sedikit demi sedikit dengan menggunakan ose bulat, kemudian disuspensikan tabung reaksi yang telah diisi $\mathrm{NaCl} 0,9 \%$ steril, lalu suspensi tersebut dibandingkan kekeruhannya hingga sama dengan standar Mc.Farland 0,5 .

\section{Pemeriksaan organoleptik}

Pemeriksaan organoleptik meliputi bentuk, warna, bau. Pengamatan dilakukan secara visual terhadap sediaan sabun cair.

\section{Uji Homogenitas}

Uji homogenitas gel dilakukan dengan mengambil lebih kurang 0,5gram gel pada masing-masing formula. Kemudian dioleskan pada plat kaca, diraba dan digosokkan, massa gel harus menunjukkan susunan yang homoge dengan indikator tidak terasa adanya bahan padat kasar pada kaca.

\section{Uji pH}

Pengukuran $\mathrm{pH}$ dilakukan dengan menggunakan $\mathrm{pH}$ meter. Alat dicelupkan kedalam sampel gel yang telah diencerkan dengan akuades, diamkan beberapa saat dan hasilnya dicatat disesuaikan $\mathrm{pH}$ kulit. $\mathrm{pH}$ sediaan yang memenuhi kriteria $\mathrm{pH}$ kulit yaitu dalam interval 4,5 - 6,5.

\section{Uji Tinggi Busa}

Busa merupakan salah satu parameter yang paling penting dalam menentukan mutu produk-produk kosmetik, terutama sabun. Tujuan pengujian busa adalah untuk melihat daya busa dari sabun cair. Busa yang stabil dalam waktu lama lebih diinginkan karena busa dapat membantu membersihkan tubuh Dimasukkan formula sabun ke dalam tabung berskala yang berisi $10 \mathrm{ml}$ aquades dan kemudian di tutup. Tabung dikocok selama 20 detik dan diukur tinggi busa yang terbentuk.

\section{Uji Kestabilan Busa}


Stabilitas busa dinyatakan sebagai ketahanan gelembung sabun untuk mempertahankan ukuran atau ketahanan pecahnya lapisan film dari gelembung. Stabilitas busa setelah 5 menit busa harus mampu bertahan antara 60-70\% dari volume awal. Dimasukkan ke dalam tabung berskala yang berisi 10 ml aquades dan kemudian di tutup. Tabung dikocok selama 20 detik dan diukur tinggi busa yang terbentuk., tabung didiamkan selama 5 menit, kemudian diukur lagi tinggi busa yang dihasilkan setelah 5 menit.Kemudian dicatat dan dihitung.

$$
\text { Uji busa }=\frac{\text { Tinggi busa akhir }}{\text { Tinggi busa awal }} \times 100 \%
$$

\section{Uji Alkali Bebas}

Uji asam lemak bebas atau alkali bebas bertujuan untuk mengetahui asam lemak bebas yang berada dalam sampel sabun, tetapi tidak terikat sebagai senyawa natrium ataupun trigliserida (lemak mineral). Sedangkan alkali bebas menunjukkan banyaknya alkali dalam sabun yang tidak terikat sebagai senyawa. Sampel sabun cair ditimbang

\author{
Kadar Alkali Bebas (\%) $=\frac{\mathrm{v} \times \mathrm{N} \times 0,0561}{\mathrm{w}} \times 100 \%$ \\ Keterangan: \\ $\mathrm{V}$ : Volume HCL dalam titrasi (ml) \\ $\mathrm{N}$ : Normalitas $\mathrm{HCl}(\mathrm{N})$ \\ W: Bobot sampel (gram)
}

\section{Uji Daya Hambat}

Media yang sudah dibuat diswebkan secara merata suspensi bakteri dengan menggunakan lidi kapas steril dibiarkan agar suspensi terserap pada media. Kemudian di dalam cawan petri sekitar 5 g, kemudian dimasukkan ke dalam gelas piala $250 \mathrm{ml}$. Selanjutnya ditambahkan $100 \mathrm{ml}$ alkohol 96\%, batu didih serta beberapa tetes larutan indikator fenolftalein. Lalu dipanaskan di atas penangas selama 30 menit sampai mendidih. Bila larutan berwarna ungu kemudian dititrasi dengan larutan $\mathrm{HCl}$ $0,1 \mathrm{~N}$ dalam alkohol sampai warna ungu tepat hilang. 
Perlakuan dilakukan secara triplo untuk memastikan hasil yang didapat. Selanjutnya semua media diinkubasi ke dalam inkubator suhu $35^{\circ} \mathrm{C}$ selama 24 jam. Kemudian diukur diameter zona bening yang terbentuk dengan menggunakan penggaris millimeter. Aktivitas antibakteri diperoleh dengan mengukur zona bening pada media (Surjowardojo et al., 2015).

\section{HASIL DAN PEMBAHASAN}

Hasil uji organoleptis dan kimia sediaan gel yang meliputi uji organoleptis (bentuk, warna, dan bau), uji homogenitas, uji $\mathrm{pH}$, Tinggi busa, stabilitas busa dan kadar alkali bebas dapat dilihat pada Tabel 2.

Uji organoleptis dimaksudkan untuk menilai sediaan terhadap keberterimaan produk pada penampilan fisik sabun. Penilaian tersebut meliputi bentuk, warna dan aroma. Sabun dibentuk dari campuran asam lemak (gliserida) yang terdapat pada minyak zaitun dengan basa kuat $\mathrm{KOH}$. Reaksi yang terjadi disebut sebagai reaksi penyabuanan atau safonifikasi (Widyasanti et al., 2019)

Tabel 2. Hasil evaluasi fisik dan kimia sediaan sabun cair ekstrak etanol serai wangi

\begin{tabular}{clllll}
\hline No & Parameter Uji & F0 & F1 & F2 & \multicolumn{2}{l}{ F3 } \\
\hline 1 & Organoleptis & $\begin{array}{l}\text { Cair, kuning } \\
\text { aroma khas } \\
\text { serai }\end{array}$ & $\begin{array}{l}\text { Cair, cokelat, } \\
\text { aroma khas } \\
\text { serai }\end{array}$ & $\begin{array}{l}\text { Cair, } \\
\text { cokelat, } \\
\text { aroma khas } \\
\text { serai }\end{array}$ & $\begin{array}{l}\text { Cair, cokelat, } \\
\text { aroma khas } \\
\text { serai }\end{array}$ \\
& & Homogen & Homogen & Homogen & Homogen \\
2 & Homogenitas & 12 & 12 & 11 & 10 \\
3 & pH & $55 \mathrm{~mm}$ & $70 \mathrm{~mm}$ & $80 \mathrm{~mm}$ & $100 \mathrm{~mm}$ \\
4 & Tinggi Busa & $72,72 \%$ & $85,71 \%$ & $87,5 \%$ & $90 \%$ \\
5 & Stabilitas busa & $0,3 \%$ & $0,14 \%$ & $0,10 \%$ & $0,8 \%$ \\
6 & Kadar alkali bebas & 0,3 & &
\end{tabular}

Komposisi yang sesuai memberikan bentuk sediaan sabun yang baik. Semua formula sediaaan sabun berbentuk cair, berwarna kuning sampai cokelat dan beraroma khas ekstrak serai. Pada formula F0 bentuknya berbeda dengan formula yang lainnya. Hal ini disebabkan pada formula ini tidak terdapat ekstrak etanol serai wangi (berwarna cokelat). Sesuai dengan parameter fisik sediaan, bahwa formula sudah memenuhi persyaratan sebagai sabun cair. Syarat mutu sabun cair selain kriteria fisik (bentuk, bau dan aroma) adalah derajat keasaman $(\mathrm{pH})$. Nilai $\mathrm{pH}$ pada formula berkisar antara $\mathrm{pH}$ 10-12. Penetapan nilai $\mathrm{pH}$ bertujuan untuk mengetahui tingkat keasaman yang 
dimiliki oleh sabun cair. Secara umum produk sabun cair memiliki $\mathrm{pH}$ yang cenderung basa (Wasitaatmaja, 1997).

Bahan dasar penyusun sabun cair tersebut yaitu $\mathrm{KOH}$ sehingga menghasilkan reaksi saponifikasi dengan lemak-minyak, atau detergen sintetis yang memiliki nilai $\mathrm{pH}$ di atas $\mathrm{pH}$ netral. Permukaan kulit memiliki $\mathrm{pH}$ berkisar antara 5,5-6,0. Nilai ini dipengaruhi kadar sel tanduk yang terlepas dan pengotor lainnya yang melekat pada kulit. pH sabun yang masih dapat diterima baik oleh kulit berkisar antara $\mathrm{pH}$ 8-11. Pada formula yang dihasilkan hanya pada formula F2 dan F3 yang sesuai standar. Jika pH sabun cair tidak sesuai dengan persyaratan yang telah ditetapkan, maka akan menyebabkan lapisan tanduk kulit membengkak atau menjadi iritasi akibat kenaikan permeabilitas kulit dan mempercepat hilangnya mantel asam lemak pada permukaan kulit (Wasitaatmaja, 1997).

Parameter lainnya yang dilakukan adalah busa sabun. Karakteristik busa sabun dipengaruhi oleh kandungan bahan aktif sabun atau surfaktan pada sediaan. Zat pembusa bekerja untuk menjaga agar busa tetap terbungkus dalam lapisan-lapisan tipis, molekul gas terdispersi dalam campuran. Pada formula sabun tinggi busa berkisar antara $55 \mathrm{~mm}-100 \mathrm{~mm}$. Semakin besar ekstrak etanol serai yang terdapat pada formula maka semaikin tinggi busa yang dihasilkan. Seperti pada Gambar 1.

Pengaruh ekstrak terhadap tinggi busa (mm)

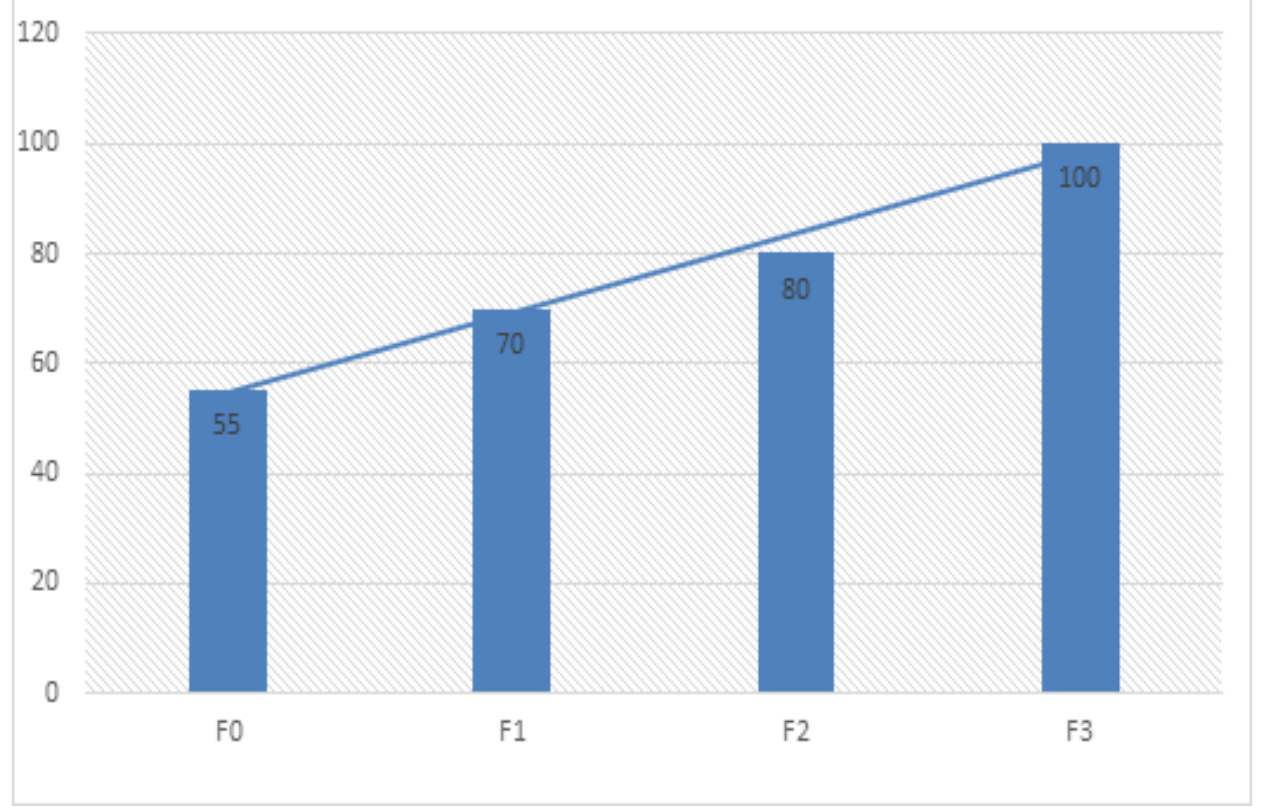


Perbedaan tinggi busa antara Formula disebabkan kandungan senyawa saponin pada formula, formula dengan kandungan ekstrak etanol yang tinggi menyebabkan secara tidak langsung mengandung saponin yang lebih banyak sehingga busa yang terbetuk semakin tinggi. Disamping itu juga stabilitas busa semakin lebih baik. Busa yang terbentuk akan lama bertahan yang pada akhirnya berkurang. Campuran yang mengandung bahan aktif sabun akan menghasilkan busa yang stabil bila dicampur dengan air. Gelembung gas yang terbentuk sulit pecah dikarenakan lapisan tipis terbentuk dengan kuat (Mumpuni dan Sasongko, 2017).

Berdasarkan SNI, standar alkali bebas pada sabun cair yaitu maksimal $0,1 \%$. Hal ini menunjukan bahwa sabun cair ekstrak etanol serai wangi sesuai dengan persyaratan yaitu kadar alkali bebas berkisar antara 0,03\% - 0,14\% Perbedaan nilai kandungan alkali bebas yang terdapat dalam formula sabun cair, disebabkan karena pada pembuatan basis sabun cair dilakukan pemanasan yang lama hingga sabun menjadi pasta yang kering sehingga kalium hidroksida yang merupakan salah satu pembentukan basis sabun sudah bereaksi dengan lemak atau minyak zaitun.

\section{Daya Hambat Sabun Cair}

Formula sediaan sabun cair ekstrak etanol serai wangi (Cymbopogon Nardus. L) dengan kosentrasi yang berbeda-beda yaitu 0\% (F0), 9\% (F1), $18 \%$ (F2) dan 24\% (F3) dilakukan pengujian efektivitas daya hambat terhadap Staphylacoccus aureus. Hasil pengujian efektivitas daya hambat sabun cair ekstrak etanol serai wangi dapat dilihat pada Tabel 3 .

\begin{tabular}{llll}
\hline No & Formula/ perlakuan & \multicolumn{2}{c}{$\begin{array}{c}\text { Rerata Diameter Zona } \\
\text { Hambat }\end{array}$} \\
\hline 1 & F0 & $19,6 \mathrm{~mm}$ & Kuat \\
2 & F1 & $22,0 \mathrm{~mm}$ & sangat kuat \\
3 & F2 & $24,6 \mathrm{~mm}$ & sangat kuat \\
4 & F3 & $39,2 \mathrm{~mm}$ & sangat kuat \\
5 & K+ & $41,4 \mathrm{~mm}$ & sangat kuat \\
6 & K- & - & - \\
\hline
\end{tabular}

\section{Keterangan:}

F0 (formula koesentrasi 0\%),

F1 (formula kosentrasi 9\%),

F2 (formula kosentrasi 18\%),

F3 (formula kosentrasi 24\%),

$\mathrm{K}+$ (kontrol positif)

$\mathrm{K}$ - (kontrol negatif) 
Karakteristik zona hambat yang terjadi pada masing masing formula ditandai dengan daerah bersih disekitar cakram, seperti pada Gambar 2.

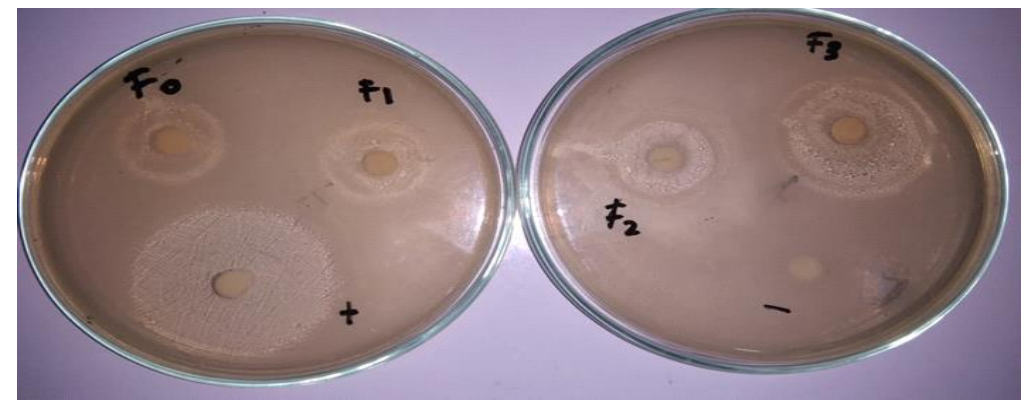

Berdasarkan Tabel 3 hasil yang diperoleh bahwa diameter zona hambat sediaan sabun cair pada formula F0, F1, F2 dan F3 mengalami peningkatan. Formula F0 yang tidak mengandung ekstrak etanol sereh wangi memberikan penghambatan pertumbuhan terhadap bakteri, hal ini disebabkan oleh komposisi dari formula sabun itu sendiri yang mengandung minyak zaitun. Minyak zaitun atau disebut dengan olive oil pada formulasi berfungsi sebagai bahan dasar sabun, selain itu senyawa oleoropein dalam minyak zaitun ternyata efektif mengganggu pertumban bakteri. Oleoropein dapat merusak membran dan peptidoglikan sel bakteri sehingga pertumbuhan bakteri terhambat (Pratama dan Andi, 2017).

Hasil formulasi sabun (F1, F2 dan F3) membuktikan bahwa formula sabun cair yang mengandung ekstrak etanol serai wangi memberikan aktivitas antibakteri terhadap pertumbuhan bakteri Staphylococcus aureus. Formula F1, F2 dan F3 lebih baik dari F0 karena terdapat ekstrak etanol sereh wangi yang terbukti mengandung senyawa sekunder yang bersifat sebagai anti bakteri. Adanya aktivitas antibakteri ditandai dengan adanya zona atau wilayah transparan disekitar cakram. Zona yang terbentuk berbeda-beda tergantung jenis dan konsentrasi zat antibakteri pada cakram. Semakin luas zona yang terbentuk akan semakin besar diameter penghambatan artinya semakin kuat zat antibakterinya (Aziz, 2019).

\section{SIMPULAN}

Formulasi sabun cair ekstrak etanol serai wangi (Cymbopogon Nardus.L) berdasarkan evaluasi karakteristik sediaan sabun cair memenuhi persyaratan sebagai sabun cair dan efektivitas daya hambat terhadap pertumbuhan Staphylococcus aureus terbesar adalah formula F3 (kosentrasi ekstrak 24\%) dengan kategori kuat. 


\section{UCAPAN TERIMAKASIH}

Terima kasih pada keluarga, temanteman, dosen, staf sekretariat dan laboratorium atas masukan dan banyak membantu selama proses berlangsung,

\section{DAFTAR PUSTAKA}

Aziz. Analisis in vitro aktivitas antibakteri daun sisik naga (Drymoglossum pilosellaoides) terhadap bakteri Vibrio harveyi dan Vibrio parahaemolyticus. Fakultas Perikanan dan Ilmu Kelautan, Universitas Borneo Tarakan. 2019. Journal of Aquaculture and Fish Health Vol. 8 No.2.

Badan Standarisasi Nasional. Standar Nasional Indonesia. Sabun Mandi Cair. Jakarta. 1996. Pp 1-10.

Basuki D. Aktifitas Antibakteri Ekstrak

Etil Asetat Tanaman Serai (Cymbopogon nardus (L.) Rendle) Terhadap Escherichia coli Dan Staphylococcus aureus Multiresisten Serta Bioautografinya. Skripsi Jurusan Farmasi Fakultas Farmasi Universitas Muhammadiyah Surakarta. 2011.

Mumpuni A.S dan Sasongko Heru. 'Mutu Sabun Transparan Ekstrak Etanol Herba Pegagan (Centella asiatica L.) setelah Penambahan Sukrosa. Universitas sebelas maret, surakarta. Vol.7, No.1. 2017, Hal. 71-78 ISSN: 20884559.

Pratama N dan Andi Ilham. Pengaruh Kadar Minyak Zaitun dalam Krim Ekstrak Daun Camelia Sinensis L Terhadap Karakteristik Fisik dan Aktivitas Antibakteri S.aureus. Skripsi Program Studi Farmasi Fakultas Ilmu Kesehatan Universitas Muhammadiyah Malang. 2017.

Sukawaty Y, Husul W, Ananda VA. Formulasi sediaan sabun mandi padat ekstrak etanol umbi bawang tiwai (Eleutherine bulbosa (mill.) Urb.). Akademi Farmasi Samarinda. Media Farmasi vol. 13 no. $1.2016: 14-22$

Surjowardojo P, Tri E.S, Gabriel R.Sirait. Daya hambat dekok kulit apel manalagi (Malus sylvestrs Mill.) terhadap pertumbuhan Staphylococcus aureusdan Pseudomonas sp. penyebab mastitis pada sapi perah. Fakultas Peternakan, Universitas Brawijaya, Malang. 2015. J. Ternak Tropika Vol. 16, No.2: 4048.

Tong, S.Y.T., Davis, J.S., Eichenberger, E., Holland, T.L., Fowler, F.G. Staphylococcus aureus infections: Epidemiology, pathophysiology, clinical manifestations, and management. Clinical 
Microbiology Reviews, 2015. 28(3), 603-66.

Wasitaatmadja, S.M. Penuntun Ilmu Kosmetik Medik. Penerbit Universitas Indonesia. Jakarta. 1997.

Widyasanti A, Adryani TW dan Rosalinda S. Pembuatan Sabun
Mandi Cair Berbahan baku Minyak Kelapa Dengan Berbagai Variasi Konsentrasi Ekstrak Teh Putih. Departemen Teknik Pertanian Universitas Padjadjaran, Bandung. 2019. Agrointek Vol.13 No.2. DOI: http://dx.doi.org/10.21107/agroint ek.v13i2.5102. 